\title{
Study of Bacteriological Profile and Antibiogram of Bile in Patients with and Without Gall-Stones
}

\author{
R. Ambica*, Bhavesh Rathod C. Bhavana \\ Department of Microbiology, Bangalore Medical College and Research Institute, \\ Karnataka, India \\ *Corresponding author:
}

\section{Keywords}

Bacteriological profile,

Bile,

Gall-stones

Article Info

Accepted:

20 March 2019

Available Online:

10 April 2019

\section{A B S T R A C T}

This is a prospective study done in 2 tertiary care hospitals and a super-specialty hospital attached to a medical college. 50 patients undergoing cholecystectomy were included in the study. Patients with even a single macroscopic gall-stone anywhere in the biliary tract were included in Category-A and the rest in Category-B. The aim of the project was to find out the difference, if any, in the bacteriological profile and antibiogram of bile in patients in these two categories which cover most of the causes of cholecystitis, and help in better management of these patients especially in places where facilities to drain and culture bile are not available. The bile collected was immediately taken to microbiology department and inoculated into Selenite-F broth and BHI broth and incubated at $37^{\circ} \mathrm{C}$. Cultures were performed on sheep blood agar and MacConkey agar. Bacterial identification was done based on standard biochemical reactions and antibiogram performed as per CLSI guidelines 2014. 68\% of Category-A patients had positive culture in contrast to $80 \%$ in Category-B. Category-A was dominated by females in their 5th and 6th decade while Category-B had males in their 6th and 7th decade. Klebsiella and E.coli were equally frequent in Category-A patients while the Category-B was dominated by E.coli. Enterococcus was third most common (13.5\% of all positive cases). Pseudomonas, Gram negative non fermenters (GNNF) covered the rest. Cholangiocarcinoma was more prone to bacterial invasion than peri-ampullary carcinoma. Only around $8.1 \%$ of the cases are associated with poly-microbial infection. There seemed to be some association between biliary stricture and GNNF. Antibiogram was almost similar in the two categories with overall in vitro sensitivity being maximum with Amikacin (81\%), followed by Piperacillin-tazobactum (77\%), and Gentamicin (64\%). Cefepime (13\%), Ampicillin (22\%), Amoxicillin-Clavulanate (23\%), Cefotaxime (27\%), Ciprofloxacin (29\%) showed poor sensitivity.

\section{Introduction}

Once considered the disease of West and affluent, today gall-stones and other gallbladder diseases are establishing themselves in developing countries also'. Infection of gall-bladder and its complications is an important cause of morbidity and mortality in these patients ${ }^{2}$. The pathogenesis of bile infection is incompletely understood, with the prevailing theories not fully explaining all the observations $^{3}$. 
Acute cholangitis refers to inflammation of the biliary ductal system from bacterial or non-bacterial infection, usually in the setting of biliary obstruction ${ }^{4}$. The main factors in the pathogenesis of the acute cholangitis are biliary tract obstruction, elevated intraluminal pressure and infection of bile $e^{5}$. The bile is normally sterile but in the presence of obstruction, the chances of cholangitis increases ${ }^{2}$.

The micro-organisms are proposed to enter the biliary tree from duodenum, through portal vein, etc., though with varying levels of certainity $^{2}$. There are some studies on microbiological profile of bile in gall bladder diseases which have shown that the risk for infection development varies with the primary condition $^{6,7,8}$. Thus, different gall bladder diseases differ in probability of developing infection and also the micro-organisms involved in it, depending on the route of entry of micro-organisms. There are only a few, if any, microbiological studies on various gall bladder diseases individually, excepting gall stones. Thus there is a need of data for infections secondary to other causes, which might help the doctor use a more appropriate antibiotic specific to patient's condition. But since infection is usually due to gall-stones $60-80 \%$ of the times ${ }^{[3,9]}$, and that the other causes like obstructing primary tumours, gallbladder carcinoma, benign strictures, primary stenosing cholangitis, parasites and hemobilia $^{2}$, altogether constitute only $20-30 \%$ of the cases, microbiological study of individual problems is difficult, and less accurate.

This analysis inspired us to attempt on finding the common bacterial flora in patients with other gall-bladder conditions. We grouped the patients into two, one with gall-stones and one without gall-stones but with some other underlying gall-bladder conditions, which would include all other risk factors for infection mentioned above. We found the common microbial flora in the two groups and the antibiotic susceptibility patterns, and thus helping in judicious use of antibiotics.

\section{Materials and Methods}

This prospective study on bile was carried out in two tertiary care hospitals and a superspecialty hospital attached to Bangalore Medical College and Research Institute, over a period of two months in 2017. Total of 50 patients diagnosed with cholecystitis and undergoing cholecystectomy were included in this study which comprised of 25 patients having gall-stones, labeled as Category-A and 25 patients having no gall-stones but other pathology which was responsible for their cholecystitis, labeled as Category-B.

$5 \mathrm{ml}$ of bile sample was collected in a sterile container with permission of the operating surgeon using standard precautions, and was appropriately labelled to include the patient's name and the presence or absence of gallstones, to avoid mixing of the data. It was immediately taken to the Microbiology department and $1 \mathrm{ml}$ of the bile was inoculated into BHI broth and another $1 \mathrm{ml}$ of bile was inoculated into Selenite F broth. Then, direct streaking of bile on 5\% sheep blood agar and MacConkey agar medium was done and maintained at $37^{\circ} \mathrm{C}$ overnight.

After 6 hrs of incubation in Selenite F broth, sub-culture on blood agar was done. And after overnight incubation in BHI broth, subcultures were done in both MacConkey and Blood agar culture media.

The isolates were identified by standard biochemical reactions ${ }^{10}$ and were subjected to antibiotic susceptibility testing as per CLSI guidelines $2014^{11}$ by modified Kirby-Bauer disk diffusion technique on Muller Hinton agar. 


\section{Results and Discussion}

\section{Category-A}

Out of 25 patients belonging to this group, 19 (76\%) were females and 6(24\%) were males (Table 1). The average age was 51 years (females - 47 years; males - 58 years). $68 \%$ of the cases were positive for bacterial growth. E. coli and Klebsiella were the most frequently isolated bacteria accounting for $41.17 \%$ and $35.29 \%$ of the positive cases respectively. Together they were responsible for $52 \%$ of all the cases or $76.47 \%$ of the culture positive cases. Pseudomonas, other Gram negative non fermenters and Enterococcus covered the rest of the positive cases. Poly-microbial growth was less frequent (4\%). Resistance was common among bacteria for Ampicillin (14\%), Amoxicillin-Clavulanate (9\%), and Cefepime (14\%). Bacteria were sensitive to Amikacin (81\%), Piperacillin-Tazobactum (78\%) and Gentamicin (69\%). Co-trimoxazole (45\%) and Ertapenem (50\%) also showed relatively favorable sensitivity pattern.

Two cultures yielded Pseudomonas which were multi-drug resistant. One was resistant to Gentamicin, Ciprofloxacin, Amikacin, Imipenem, Cefepime, Aztreonam, Ceftazidime, Ticarcillin and Piperacillin, and sensitive only to Polymyxin-B. The other case where pseudomonas was isolated was resistant to Cefotaxime, AmoxicillinClavulanate, Piperacillin-Tazobactum, Cefepime, Aztreonam, Ceftazidime, and Piperacillin, but was sensitive to Imipenem.

\section{Category-B}

Out of 25 patients belonging to this group, 8 (32\%) were females and $17(68 \%)$ were males (Table 1). The average age was 57 years (females - 49 years; males - 60 years). This category is composed of peri-ampullary carcinoma, Cholangiocarcinoma, biliary stricture, carcinoma of gall-bladder, mass in the head of pancreas. The age-wise distribution of these cases is depicted in Figure 2. $80 \%$ of the cases were positive for bacterial growth. Case-wise distribution of micro organisms and antibiotic sensitivity is given in Table 2. E. coli was very much more frequent than Klebsiella in the ratio of 3.25:1 and were together responsible for $85 \%$ of the positive cases. Gram negative non fermenters and Enterococcus covered the rest of the positive cases. Poly-microbial growth was not infrequent (8\%). Resistance was common among organisms for Ampicillin (27\%), Cefotaxime (11\%), Amoxicillin-Clavulanate (31\%) and Cefepime (13\%). The organisms were sensitive to Amikacin (80\%), Piperacillin-Tazobactum (76\%), and Gentamicin (60\%).

The comparison of bacterial isolation pattern and antibiotic susceptibility pattern in Category A and B is depicted in Table 3 and Figure 1 respectively.

Total of 50 patients were included in this study which comprised of 25 patients having a gall-stones and 25 patients having no gallstone but having other pathology which was responsible for their cholecystitis. Those with gall-stones were labelled category-A patients and the others as category-B patients. The median age of patients was 54 years. Male:Female ratio was $0.85: 1$.

Patients belonging to category $\mathrm{A}$ had a median age of 51 years with female to male ratio being 3.16:1. Thus, gall-stone disease is predominantly a disease of females in $5^{\text {th }}$ and $6^{\text {th }}$ decade of their lives. The culture positivity was seen in $68 \%$ of the cases, slightly higher from other studies probably because ours is a tertiary care hospital and also because we were able to inoculate and streak the sample within an hour. Manan et al., ${ }^{3}$ (2014) had an 
isolation rate of $58.73 \%$ while Capoor et al., ${ }^{6}$ (2008) had an isolation rate of $32 \%$. Only one case showed a polymicrobial growth. $E$. coli and Klebsiella dominated the scene in this category with each of them almost equally frequent covering $76.47 \%$ of all the positive cultures. This finding is in consistency with findings of Capoor et al., ${ }^{6}$ (2008) and Manan et al., ${ }^{3}(2014)$. Two cases gave growth of Pseudomonas which was resistant to almost all the drugs with only a drug or two being spared. The organism showed significant resistance to ampicillin with only $14 \%$ of the cultures being sensitive to it. This was also noted in the studies of others. Amoxicillin-Clavulanate also showed very low efficacy, with only $9 \%$ of the cultures being sensitive to it. The sensitivity rates with Cefepime and Ciprofloxacin were also very low, with only $14 \%$ and $22 \%$ of the cases yielding sensitive organism respectively. Amikacin (81\%) and Piperacillin-Tazobactum (78\%) were the most effective antibiotics for this category of patients. Gentamicin (69\%) also showed favorable sensitivity patterns. This is in contrast to the findings of Manan et al., ${ }^{3}$ (2014) and Shenoy et al., ${ }^{7}(2014)$ who found that most bacteria were sensitive to cephalosporins, indicating the regional variation of resistance pattern. Even Capoor et al., ${ }^{6}$ (2008) found Piperacillin-Tazobactum very sensitive. According to $\mathrm{Wu}$ et al., ${ }^{12}$, the stone may be acting as a source of infection with the bacteria trapped in the centre. In such cases, it becomes imperative to remove the stones prior to antibiotic therapy.

Patients belonging to Category- $\mathrm{B}$ had a median age of 57 years with female to male ratio being $0.47: 1$. Thus aculculous cholecystitis requiring surgical intervention is usually a disease of males in the $6^{\text {th }}$ and $7^{\text {th }}$ decade of their lives. This category is composed of peri-ampullary carcinoma, Cholangiocarcinoma, biliary stricture, carcinoma of gall-bladder, mass in the head of pancreas, etc. All these cases are associated with some form of biliary obstruction and biliary stasis probably indicating biliary stasis as the main cause for bacterial invasion. Based on their study findings, Yusoff et al., ${ }^{2}$ (2003)also concluded that biliary stasis was responsible for infection. The culture positivity was noted in $80 \%$ of the cases with 2 cases showing multi-bacillary growth representing $8 \%$ of the total number of cases or $10 \%$ of the positive cases. This is again expectable based on the consideration that these pathologies were responsible for a long period of obstruction of biliary tract. E. coli alone dominated the scene with $E$. coli to Klebsiella isolation frequency being 3.25:1 with E. coli alone contributing to $65 \%$ of the positive cases. Klebsiella accounts for $20 \%$ of the positive cases. Enterococcus was responsible for $15 \%$ of the positive cases. Also, two cases yielded Gram negative nonfermenters.

The commonest pathology in this group was Peri-ampullary carcinoma accounting for 10 cases or $40 \%$ of the cases in this group. It showed male preponderance $(\mathrm{M}: \mathrm{F}=7: 3) .70 \%$ of the cases yielded positive culture but not a single case was associated with multibacillary growth. E. coli dominated the scene with $E$. coli representing $86 \%$ of the positive cases. Klebsiella represented $14 \%$ of the positive cultures. So, compared to the $80 \%$ isolation rate as a whole in this category, it was less frequently associated with bacterial isolation.

On the other hand, cholangiocarcinoma which represented $24 \%$ of cases in this category, there was $100 \%$ bacterial isolation rate with $33.3 \%$ cases showing multi-bacillary growth. So, it is relatively more prone to develop bacterial infection. This probably is because of the early obstruction of the biliary tract as compared to peri-ampullary carcinoma and 
hence again indicating that obstruction is the main cause for bacterial invasion. $100 \%$ of the cases showed presence of $E$. coli. One case additionally had Klebsiella, and the other had Enterococcus. Male to female ratio was 5:1.

Gall-bladder carcinoma accounted for 3 cases in this category. All the three were females in their $6^{\text {th }}$ decade. This was associated with culture positivity in all the 3 cases. Two cases yielded Klebsiella and one case yielded $E$. coli. Biliary stricture as mentioned had Gram negative non fermenter in both the cases.

One case of metastatic pancreatic head mass yielded Enterococcus. Another case of nonneoplastic head mass yielded $E$. coli. One case of carcinoma of head of pancreas yielded no growth.

We had also got a case of Caroli's disease which was diagnosed on surgical table which yielded no growth.

If it is obstruction that is responsible for bacteria to invade biliary tree, then there should have been similar isolation pattern with and without gall-stones.

This cannot be used to explain why E. coli is thrice as common as Klebsiella in patients without gall-stones.

If we think that prolonged obstruction causes E. coli to take over Klebsiella then similar finding would have been seen in Category-A patients. Those who had prolonged obstruction or long history of symptoms would show selectively E. coli. But we didn't find any such selection. It is possible that malignancy induced immune-depression may be responsible for selective $E$. coli dominance.

Resistance was common among bacteria for Ampicillin (27\%), Cefotaxime (11\%),
Amoxicillin-Clavulanate (31\%) and Cefepime (13\%). Bacteria were sensitive to Amikacin (80\%), Piperacillin-Tazobactum $(76 \%)$, and Gentamicin $(60 \%)$.

There was not much difference in the antibiotic sensitivity pattern of the isolated bacteria from the two cases as a whole as is evident from Figure 1. Morever, there was no significant difference in antibiotic sensitivity pattern of the E. coli (Fig. 2) and Klebsiella (Fig. 3) separately from the two categories.

The antibiotic sensitivity patterns of the bacteria isolated from cholangiocarcinoma and peri-ampullary carcinomais shown in Figure 4.

Putting it all together, 74\% of the cases were associated with positive culture. Shenoy et al., ${ }^{7}$ (2014) had an isolation rate of $54 \%$ while Claesson B et al., ${ }^{8}(1984)$ had an isolation rate of $72 \% .54 \%$ of the positive cases gave E. coli. $27 \%$ of the cases were positive for Klebsiella.

So, E. coli was overall twice as frequent as Klebsiella. Other bacteria included Enterococcus (13.5\%), Gram negative nonfermenter (8.1\%), Pseudomonas (5.4\%). Polymicrobial growth was seen in $8.1 \%$ of the cases.

This in contrast with very high polymicrobial infection rate of $69.5 \%$ in study of Sahu et al., ${ }^{9}$ and $31.5 \%$ in study of Shenoy et al., ${ }^{7}(2014)$.

Overall, Amikacin (81\%), PiperacillinTazobactum (77\%), and Gentamicin(64\%) showed favourable sensitivity. Cefepime (13\%), Ampicillin (22\%), AmoxicillinClavulanate (23\%), Cefotaxime (27\%), Ciprofloxacin $(29 \%)$ showed poor sensitivity (Fig. 5 and 6). This was in consistency with M K Sahuet al., ${ }^{9}$ who also found significant resistance of bacteria to third generation Cephalosporins and Ciprofloxacin. 
Table.1 Age-wise distribution of the cases in Category A and B

\begin{tabular}{|l|l|l|l|l|}
\hline \multirow{2}{*}{ Age range of the patients } & \multicolumn{2}{|l|}{ Category-A } & \multicolumn{2}{l|}{ Category-B } \\
\cline { 2 - 5 } & Male & Female & Male & Female \\
\hline 20-30 years & 0 & 5 & 0 & 1 \\
\hline $\mathbf{3 1 - 4 0}$ years & 0 & 3 & 1 & 1 \\
\hline 41-50 years & 2 & 3 & 1 & 2 \\
\hline $\mathbf{5 1 - 6 0}$ years & 1 & 2 & 3 & 3 \\
\hline 61-70 years & 3 & 3 & 7 & 1 \\
\hline $\mathbf{7 1 - 8 0}$ years & 0 & 1 & 4 & 0 \\
\hline$>\mathbf{8 0 0}$ years & 0 & 2 & 1 & 0 \\
\hline \multicolumn{1}{|c|}{ Total } & 6 & 19 & 17 & 8 \\
\hline
\end{tabular}

Table. 2 Case-wise distribution of bacterial growth among Category - B

\begin{tabular}{|c|c|c|c|c|c|}
\hline Pathology & $\begin{array}{l}\text { Number } \\
\text { of cases }\end{array}$ & $\begin{array}{l}\text { Median } \\
\text { age }\end{array}$ & $\begin{array}{l}\text { Percentage } \\
\text { culture } \\
\text { positivity }\end{array}$ & Bacterial profile & $\begin{array}{l}\text { Sensitive } \\
\text { antibiotics }\end{array}$ \\
\hline $\begin{array}{l}\text { Carcinoma of head of } \\
\text { pancreas }\end{array}$ & 1 & 52 & 0 & - & - \\
\hline Carcinoma of gall-bladder & 3 & 55 & $100 \%$ & $\begin{array}{l}\text { Klebsiella- } 66.6 \% \\
\text { E. coli- } 33.3 \%\end{array}$ & $\begin{array}{l}\text { Amikacin } \\
\text { Piperacillin- } \\
\text { Tazobactum } \\
\text { Ertapenem }\end{array}$ \\
\hline Cholangiocarcinoma & 6 & 64 & $100 \%$ & $\begin{array}{l}\text { Multibacillary in } 33.3 \% \\
\text { E. coli- } 100 \% \\
\text { Klebsiella- } 16.6 \% \\
\text { Enterococcus- } 16.6 \%\end{array}$ & $\begin{array}{l}\text { Amikacin } \\
\text { Piperacillin- } \\
\text { Tazobactum } \\
\text { Cefotaxime } \\
\text { Gentamicin }\end{array}$ \\
\hline Peri-ampullary carcinoma & 10 & 66 & $70 \%$ & $\begin{array}{l}\text { E. coli- } 86 \% \\
\text { Klebsiella- } 14 \%\end{array}$ & $\begin{array}{l}\text { Amikacin } \\
\text { Piperacillin- } \\
\text { Tazobactum } \\
\text { Ertapenem }\end{array}$ \\
\hline Billiary stricture & 2 & 63 & $100 \%$ & GNNF- $100 \%$ & $\begin{array}{l}\text { Gentamicin } \\
\text { Piperacillin- } \\
\text { tazobactum }\end{array}$ \\
\hline $\begin{array}{l}\text { Metastatic pancreatic head } \\
\text { mass }\end{array}$ & 1 & 45 & $100 \%$ & Enterococcus- $100 \%$ & $\begin{array}{l}\text { Ampicillin } \\
\text { Ciprofloxacin }\end{array}$ \\
\hline $\begin{array}{l}\text { Non-neoplastic pancreatic } \\
\text { head mass }\end{array}$ & 1 & 31 & $100 \%$ & E. coli- $100 \%$ & $\begin{array}{l}\text { Ampicillin } \\
\text { Gentamicin } \\
\text { Sensitive to almost } \\
\text { all drugs. }\end{array}$ \\
\hline Caroli's disease & 1 & 24 & $0 \%$ & - & - \\
\hline
\end{tabular}


Table.3 Comparison of Bacterial isolation pattern in the two categories

\begin{tabular}{|l|c|c|}
\hline Bacteria & $\begin{array}{c}\text { Patients with gall- } \\
\text { stones(n=25) }\end{array}$ & $\begin{array}{c}\text { Patients without } \\
\text { gall-stones } \\
(\mathbf{n = 2 5})\end{array}$ \\
\hline E. coli & $7(28 \%)$ & $13(52 \%)$ \\
\hline Klebsiella & $6(24 \%)$ & $4(16 \%)$ \\
\hline Pseudomonas & $2(8 \%)$ & $0(0 \%)$ \\
\hline GNNF & $1(4 \%)$ & $2(8 \%)$ \\
\hline Enterococcus & $2(8 \%)$ & $3(12 \%)$ \\
\hline Polymicrobial growth & $1(4 \%)$ & $2(8 \%)$ \\
\hline Overall positive culture & $17(68 \%)$ & $20(80 \%)$ \\
\hline No growth & $8(32 \%)$ & $5(20 \%)$ \\
\hline
\end{tabular}

Fig.1 Gender-wise distribution of the cases in Category B

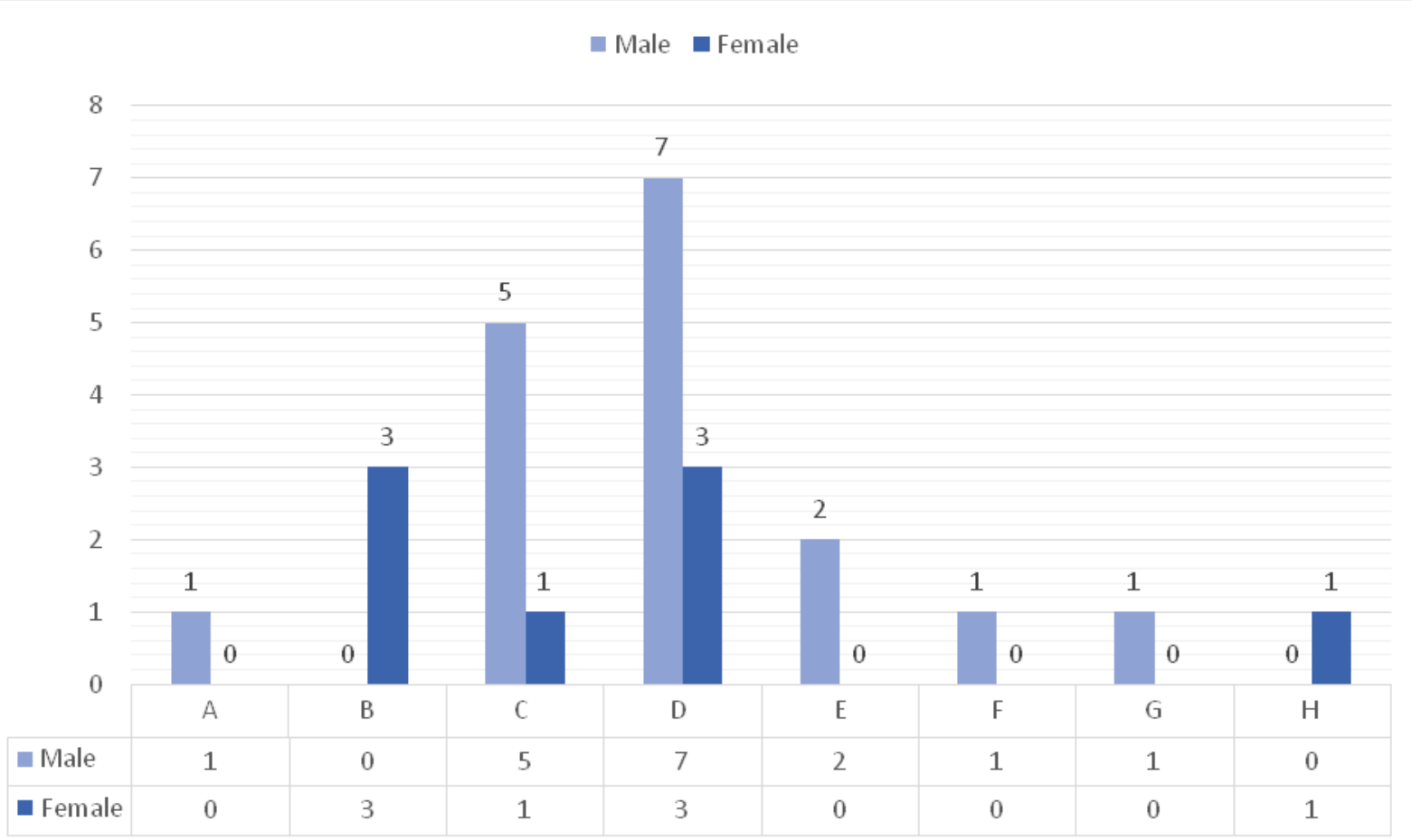
A- Carcinoma of head of pancreas.
B- Carcinoma of gall-bladder.
C- Cholangiocarcinoma
D- Peri-ampullary carcinoma
E- Biliary stricture
F- Metastatic pancreatic head mass
G- Non-neoplastic pancreatic head mass
H- Caroli's disease. 
Fig.2 Antibiotic sensitivity pattern of the two categories

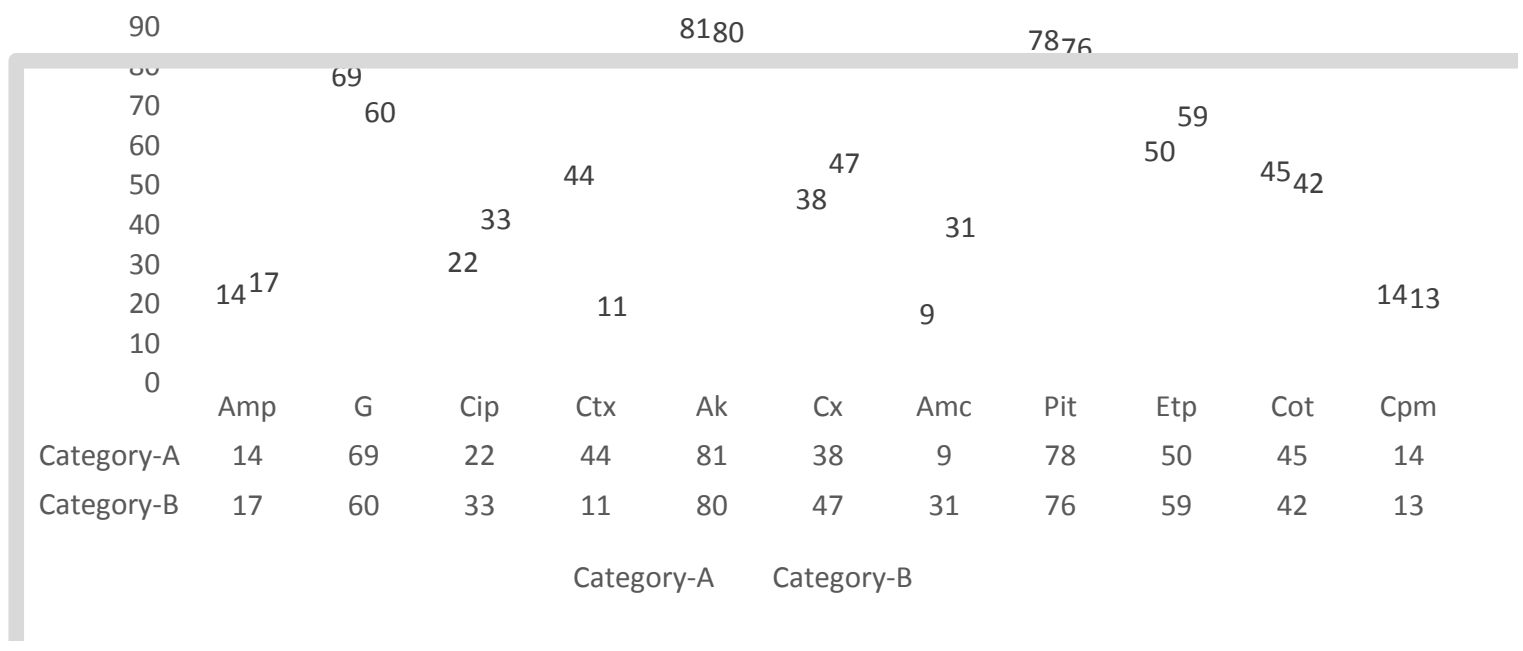

Fig.3 Comparison of antibiotic sensitivity of the E. coli in the two categories

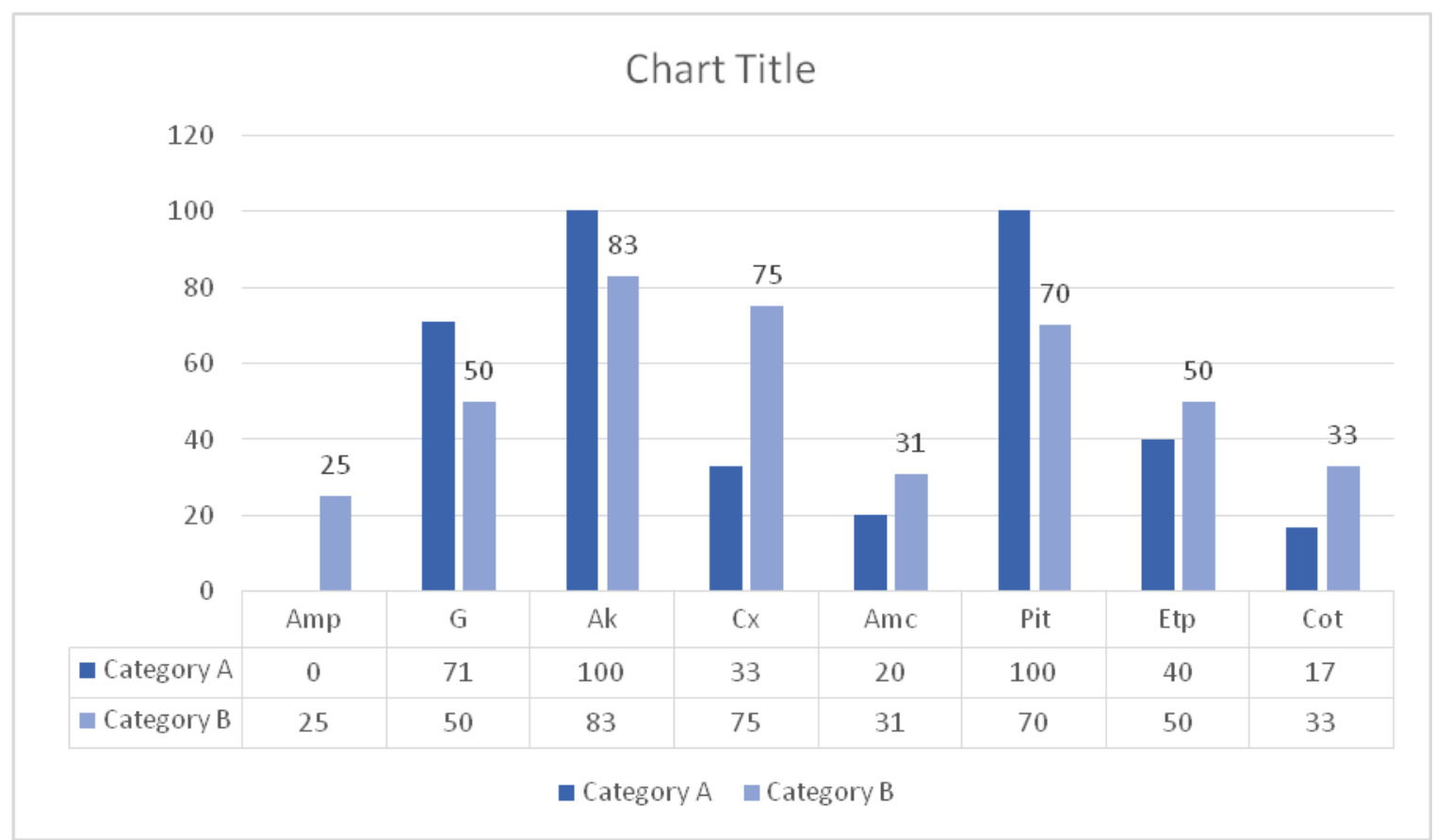


Fig.4 Comparison of antibiotic sensitivity of the Klebsiella in the two categories

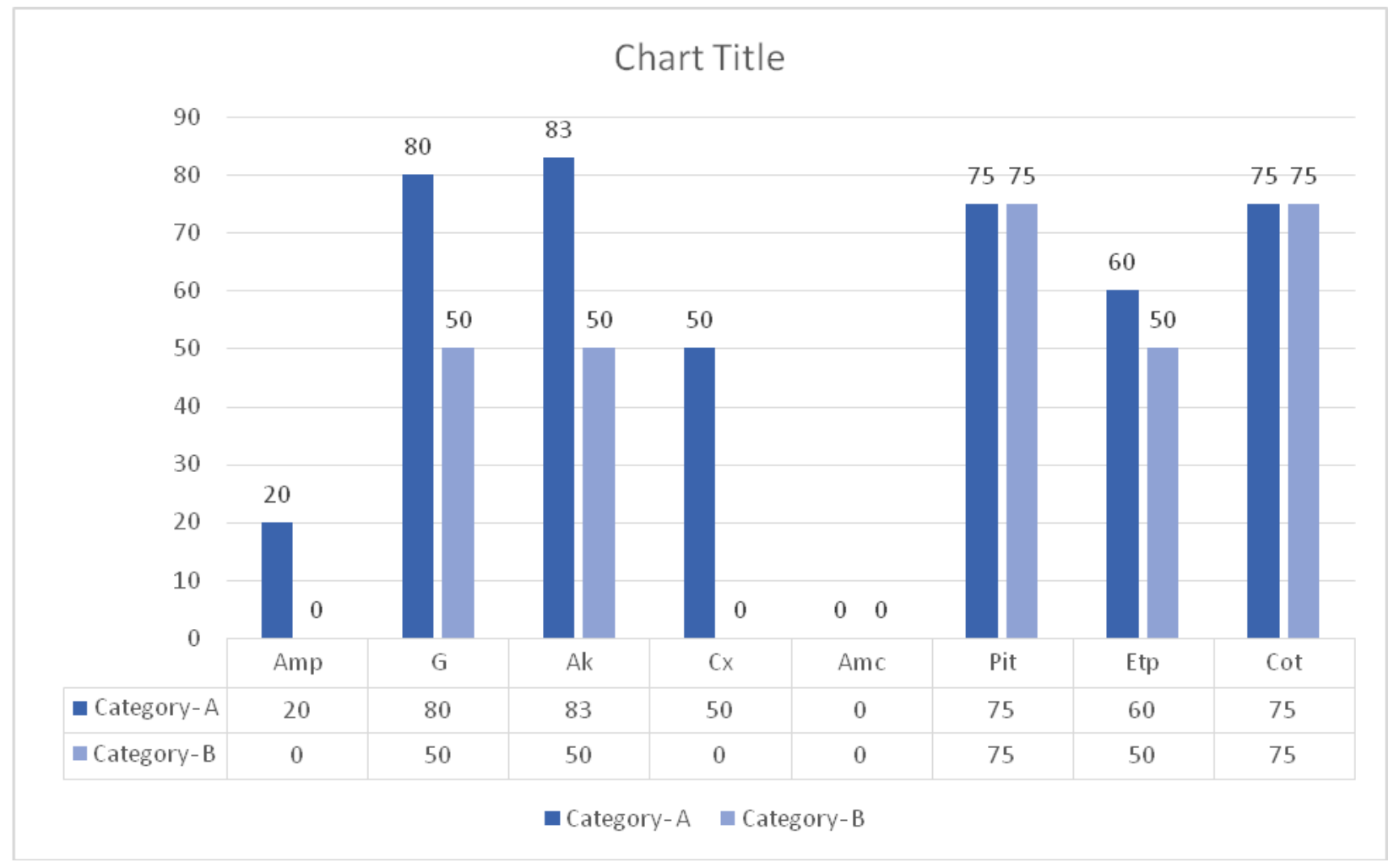

Fig.5 Comparison of antibiotic sensitivity pattern among peri-ampullary carcinoma and cholangiocarcinoma

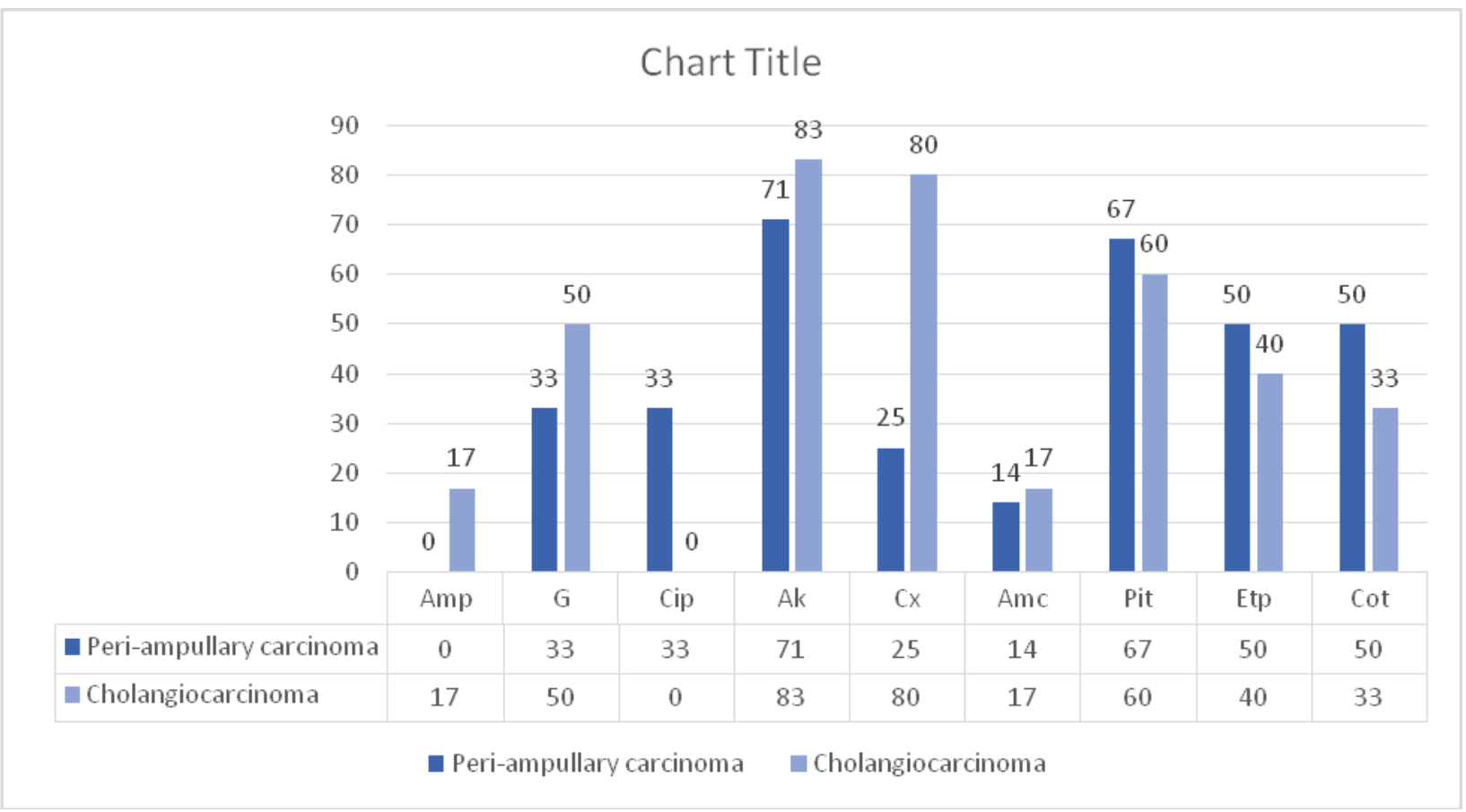


Fig.6 Overall antibiotic sensitivity pattern in gall-bladder diseases

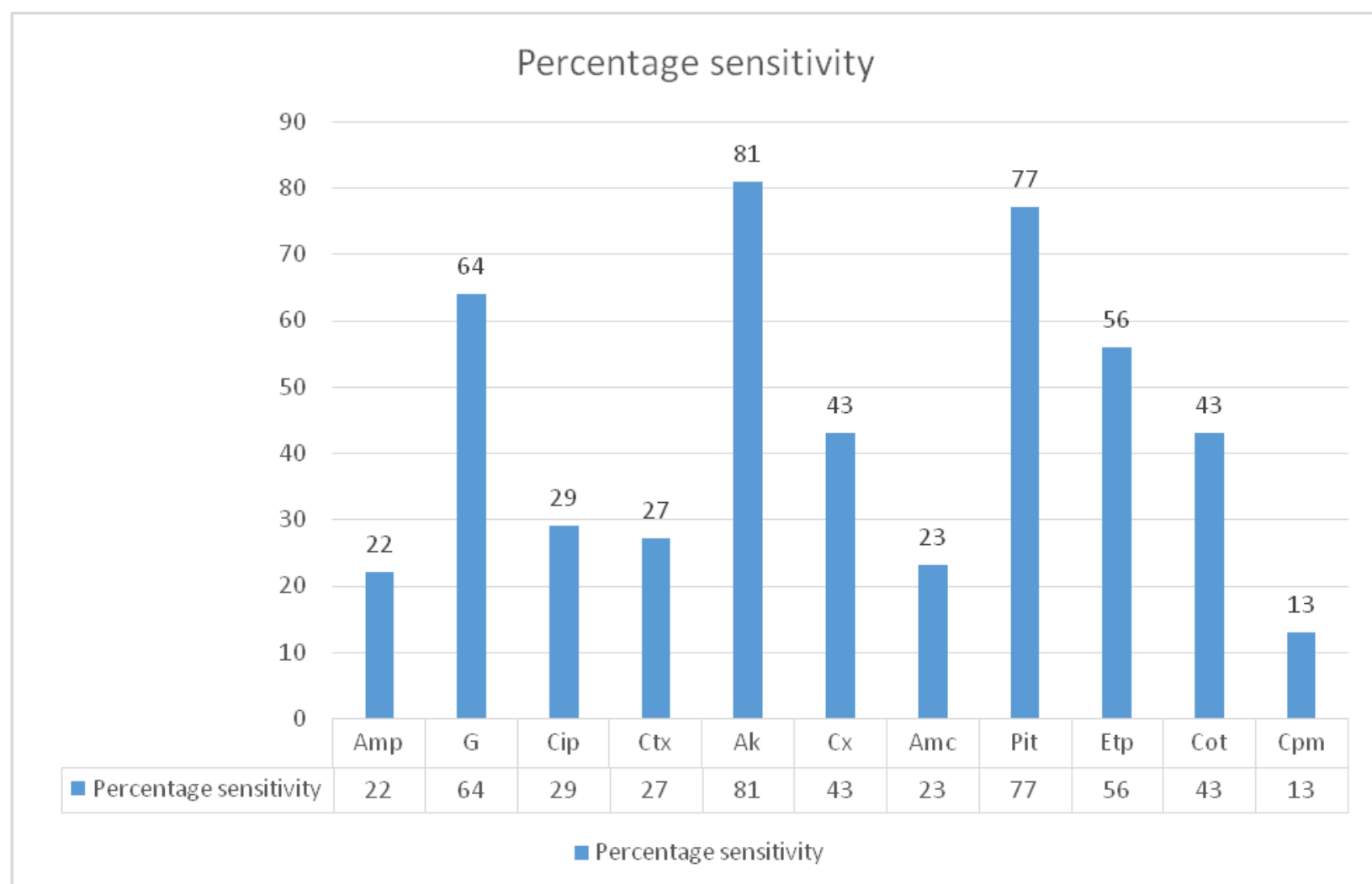

In conclusion, $68 \%$ of the cases with gallstones have a detectable bacterium in their bile, while $80 \%$ of the patients with aculculous cholecystitis requiring surgical intervention have some bacteria in their bile. The second group basically refers to malignancies of the hepato-biliary system and pancreas. Gall-stone disease is predominantly a disease of female in their $5^{\text {th }}$ and $6^{\text {th }}$ decade while malignancies of the biliary tract and pancreas are diseases of males in their $6^{\text {th }}$ and $7^{\text {th }}$ decade. E. coli is twice more common than Klebsiella overall. Inturn, Klebsiella is twice more common than Enterococcus overall. Patients with gall-stone have almost equal chance of E. coli and Klebsiella invasion while in the malignancies $E$. coli is thrice more commoner. Amikacin, PiperacillinTazobactum and Gentamicin are preferable antibiotics for cholecystitis. Cefepime, Ampicillin, Amoxicillin-Clavulanate, Ciprofloxacin, cefotaxime were usually ineffective. To tell about the association of biliary stricture with Gram negative nonfermenter would require a larger sample size.

\section{References}

1. Sachdeva S, Khan Z, Ansari MA, Khalique N, Anees A. Lifestyle and Gallstone Disease: Scope for Primary Prevention. Indian J Community Med. 2011 Oct; 36(4):263-7.

2. Yusoff IF, Barkun JS, Barkun AN. Diagnosis and management of cholecystitis and cholangitis. Gastroenterol Clin North Am. 2003; 32: 1145-68.

3. Manan F, Khan MA, Khan M. Frequency of common bacteria and their antibiotic sensitivity in patients with symptomatic cholelithiasis. J Postgrad Med Inst 2014; 28(2): 177-83.

4. Qureshi WA. Approach to the patient who has suspected acute bacterial cholangitis. 
Gastroenterol Clin North Am 2006;35:409-23.

5. Rosh AJ, Manko JA, Santen S (2014) Cholangitis in emergency medicine. Brenner//Medscape 2012.

6. Capoor MR, Nair D, Rajni, Khanna G, Krishna SV, Chintamani MS, Aggarwal P. Microflora of bile aspirates in patients with acute cholecystitis with or without cholelithiasis: A tropical experience. Braz $\mathrm{J}$ Infect Dis 2008; 12: 222-5.

7. Shenoy S M, Shenoy S, Gopal S, Tantry B $\mathrm{V}$, Baliga S, Jain A. Clinicomicrobiological analysis of patients with cholangitis. Indian $\mathrm{J}$ Med Microbiol 2014;32:157-60.

8. Claesson B, Holmlund D, Mätzsch T. Biliary microflora in acute cholecystitis and the clinical implications. ActaChir Scand. 1984;150(3):229-37.
9. M K Sahu, Ashok C, A K Dutta, J A J Prakash. Microbial profile and antibiotic sensitivity pattern in acute bacterial cholangitis. Ind J Gastroenterol. 2011;30(5):204-208.

10. Collee JG, Fraser AG, Marmion BP, Simmons A. $14^{\text {th }}$ edition. New York: Churchill-Livingstone; Mackie and McCartney Practical Medical Microbiology. 1999.

11. Clinical and Laboratory Standards Institute. Performance Standards for Antimicrobial Susceptibility Testing. Twenty-Fourth Informational Supplement. M100-S24, Vol 34, No 1: Wayne, Pennsylvania; 2014. p.38-42.

12. Wu SD, Yu H, Sun JM. Bacteriological and electron microscopic examination of primary hepatic stones. Hepatobiliary Pancreat Dis Int 2006; 5: 228-31.

\section{How to cite this article:}

Ambica, R., Bhavesh Rathod Bhavana, C. 2019. Study of Bacteriological Profile and Antibiogram of Bile in Patients with and Without Gall-Stones. Int.J.Curr.Microbiol.App.Sci. 8(04): 2726-2736. doi: https://doi.org/10.20546/ijcmas.2019.804.317 